\title{
Changes in the Localization of Type I, III and IV Collagen mRNAs in the Kidneys of Hereditary Nephritic (ICGN) Mice with Renal Fibrosis
}

\author{
Kozue UCHIO ${ }^{1,2)}$, Noboru MANABE ${ }^{1) *}$, Misuzu YAMAGUCHI-YAMADA ${ }^{1)}$, Yasufumi GOTO ${ }^{1)}$, \\ Yoshie YAMAMOTO $^{2)}$, Atsuo OGURA ${ }^{3)}$ and Hajime MIYAMOTO ${ }^{1)}$ \\ ${ }^{1)}$ Unit of Anatomy and Cell Biology, Department of Animal Sciences, Kyoto University, Kyoto 606-8502, ${ }^{2)}$ Department of Veterinary \\ Sciences, National Institute of Infectious Diseases, Tokyo 162-8640 and ${ }^{3)}$ RIKEN Bioresource Center, Tsukuba-shi, 305-0074, Japan
}

(Received 26 March 2003/Accepted 16 September 2003)

\begin{abstract}
Renal fibrotic change, extreme accumulation of extracellular matrix (ECM) components in glomeruli and tubulointerstitum, is one of the characteristic features of ICR-derived glomerulonephritis (ICGN) mice. Decreased degradation of ECMs by matrixmetalloproteinases was demonstrated in kidneys of ICGN mice. To determine the balance between production and degradation of ECMs in ki dneys of ICGN mice, we examined expression of mRNAs of ECMs in those. To demonstrate the localization of type I, III and IV collagen mRNAs in kidney sections of ICGN and control ICR mice, in situ hybridization using digoxigenin-labeled oligonucleotide antisense probes for procollagen- $\alpha_{1}$ (I), $-\alpha_{1}$ (III) and $-\alpha_{1}$ (IV) mRNAs, respectively, was performed. Negative or trace expressions of type I and III collagen mRNAs were observed in the kidneys of control mice, but stronger expressions of those were seen in glomeruli and in jured renal tubules of the kidneys of ICGN mice. Moderate expression of type IV collagen mRNA was demonstrated in a part of glomeruli and renal tubules of both control and ICGN mice, and no remarkable difference was seen between them. Severe renal fibrosis, extreme accumulation of interstitial type I and III collagens is caused by increased production and decreased degradation in the kidneys of ICGN mice. Thus, the profiles of metabolism between interstitial and membranous collagens may be different in the kidneys of ICGN mice, and excessive production of interstitial collagens may be the dominant cause of renal disease in them.

KEY WORDS: extracellular matrix (ECM), ICR-derived glomerulonephritis (ICGN) mouse, in situ hybridization, type I, III and IV collagen
\end{abstract} mRNA.

J. Vet. Med. Sci. 66(2): 123-128, 2004

Institute of Cancer Research (ICR)-derived glomerulonephritis (ICGN) mice, a novel inbred strain of mice with a hereditary nephrotic syndrome of unknown etiology, were established in the National Institute of Infectious Diseases (NIID, Tokyo, Japan) and considered a good model of human idiopathic nephrotic syndrome [14-20]. The ICGN mice develop proteinuria, hypoproteinemia and hyperlipidemia, and approximately $40 \%$ of aged (more than 30 week-old) mice develop severe systemic edema. Conventional histopathological analyses demonstrated glomerular lesions consisting of thickened basement membranes of the capillary loops with irregular sprike-like protrusions and enlargement of the mesangial area accompanied by cellular proliferation $[14,15,19,20]$. Ultrastructurally, multilaminar splitting of the lamina densa of the thickened glomerular basement membrane and fusion of the epithelial foot process were noted $[14,15]$. The characteristic changes in the structure of cell-surface carbohydrates histochemically estimated with 24 different lectins were seen in the tubulointerstitial cells in ICGN mice [25]. Previously, we immunohistochemically showed that excessive accumulation of type I, III and IV collagens was demonstrated in glomeruli and tubulointerstitum of ICGN mice as compared with those of sex- and age-matched ICR mice [26, 28]. Marked deposition of type I collagen, which was not

\footnotetext{
* Correspondence to: Manabe, N., Unit of Anatomy and Cell Biology, Department of Animal Sciences, Kyoto University, Kyoto 606-8502, Japan.
}

detected in the glomeruli of ICR mice, was seen in the glomeruli of ICGN mice.

Extracellular matrices (ECMs) play important roles in maintenance of the homeostasis of renal functions, and excessive accumulation of them in kidneys leads to progression of nephropathy [3]. The maintenance of normal kidney structure and function depends on an appropriate regulation of synthesis and degradation of ECMs, and unbalance causes gradual development of the glomerular and/or tubulointerstitial fibrotic lesion [23, 24]. We compared the activities of matrix metalloproteinases (MMPs) in the kidneys of ICGN and control ICR mice [23]. The MMPs can be divided into three groups on the basis of substrate specificity [2, 7, 24, 30]: (1) the interstitial collagenases (MMP1) primarily responsible for the degradation of type I collagen, (2) the gelatinases (MMP-2 and -9) that dominantly degrade type IV collagen, and (3) the stromelysins (MMP3 ), which have a broader substrate specificity and degrade type IV and V collagens, proteoglycans and laminin. We reported that lower activities of MMP-1 and MMP-2 and -9 were demonstrated in the kidneys of ICGN mice as compared with those of ICR mice, but there was no significant difference in the MMP-3 activities between these strains [27], indicating decreased MMP activities cause abnormal accumulation of ECM in ICGN mouse kidneys. However, the mechanisms responsible for the excessive accumulation of ECMs in the kidneys of ICGN mice have not been fully understood. In the present study, to make clear the changes in synthesis levels of the ECMs, we compared the localiza- 
tion of type I, III and IV collagen mRNAs [procollagen- $\alpha_{1}$ (I), $-\alpha_{1}$ (III) and $-\alpha_{1}$ (IV) mRNAs, respectively] in the kidney sections of ICGN and ICR mice demonstrated by in situ hybridization technique.

\section{MATERIALS AND METHODS}

Animals and tissue preparation: Nephrotic ICGN mice were prepared by mating between homozygous males (nep/ nep) and heterozygous females (nep/-) at the laboratory of NIID [14-20]. Male homozygous ICGN mice (30-weekold) from a specific-pathogen-free colony in NIID and sexand age-matched ICR mice purchased from Clea Japan (Tokyo, Japan) were used. All animals were housed in autoclaved metal cages and were given a standard diet (Oriental Yeast, Tokyo, Japan) and tap water ad libitum in an air conditioned room $\left(23 \pm 1{ }^{\circ} \mathrm{C}\right)$, under controlled lighting conditions (12 hr light/12 hr dark). They received humane care as outlined in the "Guide for the Care and Use of Laboratory Animals" (Kyoto University Animal Care Committee according to NIH \#86-23; revised 2000). For biochemical analyses, urine samples during the $24 \mathrm{hr}$ before sacrifice (24-hr-urine samples) were collected, and blood samples were obtained from the cervical vein under ether anesthesia. The animals were sacrificed under deep ether anesthesia, and then the kidneys were rapidly removed. One kidney was immediately fixed in $10 \%$ neutral-buffered formalin, $\mathrm{pH} 7.4$, for conventional histopathological evaluation, while the other was put on filter paper, mounted in OCT compound (Ames, Elkhart, IN, U.S.A.), and then rapidly frozen in dry ice-isopentane mixture for histochemical measurement of total and type I collagens and for in situ hybridization.

Clinical biochemistry: To evaluate nephrotic state and loss of renal function, blood and 24-hr urine samples were examined on the basis of the following biochemical parameters. Serum and urinary albumin (sAlb and uAlb, respectively), serum creatinine ( $\mathrm{sCr}$ ) and blood urea nitrogen (BUN), serum total cholesterol (sTC) levels were enzymatically measured by an automatic analyzer (Dri-Chem 3500U, Fuji Film Co., Tokyo, Japan). All procedures were performed according to the manufacturers' protocols.

Renal histopathology: Formalin fixed kidney samples were dehydrated through a graded ethanol series and embedded in Histosec (Merck, Darmstadt, Germany). Sections $3 \mu \mathrm{m}$ thick were mounted on glass slides precoated with 3-aminopropyltriethoxysilane (Silane; Sigma Aldrich Chemical, St. Lois, MO, U.S.A.), deparaffinized with xylene and rehydrated through a graded ethanol series. For conventional histopathological evaluation, some of the sections were stained with hematoxylin and eosin. As previously reported $[6,25,26]$, the extent of glomerulosclerosis was expressed as the degree of ECM deposition, which was assessed on sections stained with Sirius red solution (saturated picric acid in distilled water containing $0.1 \%$ Sirius red F3B; BDH Chemicals, Poole, U.K.). Sirius red staining detects interstitial collagens. All slides were mounted with
Entellan (Merck), and examined by light microscopy (at least six sections/mouse). In each kidney specimen, approximately 100 glomeruli were selected at random and evaluated. Briefly, the mesangial expansion in the glomeruli scored according to the extent of the sclerotic lesion in the glomerulus, the morphological changes in the glomeruli (capillary aneurysm and hypercellularity), and tubular (cystic tubular dilation, epithelial cellular atrophy and intraluminal cast formation) and tubulointerstitial (tubulointerstitial expansion and mononuclear cell filtration around arterioles) lesions were evaluated $[6,25,26]$.

Histochemical quantification of total and type I collagens: Type I collagen levels in each kidney cortex section were measured by microquantitative methods $[6,25,26]$. Briefly, frozen sections $5 \mu \mathrm{m}$ thick were prepared on a cryostat (Jung CM1500; Leica, Heidelberg, Germany), mounted on Silane-precoated slides and fixed with cold acetone $\left(-80^{\circ} \mathrm{C}\right)$ for $5 \mathrm{~min}$. The renal medulla area of each fixed section was removed under a surgical dissecting microscope. The kidney cortex sections were incubated with rabbit anti-mouse tail type I collagen antibody (LSL, Tokyo, Japan) for $12 \mathrm{hr}$ at $4^{\circ} \mathrm{C}$, washed in phosphate buffers saline (PBS; pH 7.4), and then incubated with horseradishperoxidase-conjugated goat anti-rabbit $\mathrm{IgG}$ antibody (American Qualex, La Mirada, CA, U.S.A.) for $1 \mathrm{hr}$ at $25^{\circ} \mathrm{C}$. After washing with $50 \mathrm{mM}$ Tris-HCl-saline (pH 7.4), chromogenic substrate solution $(30 \mathrm{mM}$ phenol, $3 \mathrm{mM} 4$-aminoantipyrine and $2 \mathrm{mM} \mathrm{H}_{2} \mathrm{O}_{2}$ in $50 \mathrm{mM}$ Tris- $\mathrm{HCl}$, $\mathrm{pH} 7.4$; Wako Pure Chemicals, Osaka, Japan) was applied to each section and incubated for $10 \mathrm{~min}$, and the optical density of the solution at $450 \mathrm{~nm}$ was determined with a spectrophotometer (Ultrospec 3000, Pharmacia Biotech, Uppsala, Sweden). Type I collagen content in each section was calculated. After measurement of the type I collagen content, total collagen level in each section was measured colorimetrically [6].

In situ hybridization: As previously reported [13, 29], frozen sections $5 \mu \mathrm{m}$ thick mounted on Silane-precoated slides were fixed with $4 \%$ paraformaldehyde (Wako) in PBS for 8 min at room temperature $\left(\mathrm{RT} ; 22-25^{\circ} \mathrm{C}\right)$, treated with $0.2 \mathrm{~N}$ $\mathrm{HCl}$ for $10 \mathrm{~min}$, and then digested with proteinase $\mathrm{K}(0.5 \mu \mathrm{g}$ / $\mathrm{ml}$; Sigma) in PBS for $10 \mathrm{~min}$ at $37^{\circ} \mathrm{C}$. The sections were postfixed with $4 \%$ paraformaldehyde in PBS for $5 \mathrm{~min}$, rinsed twice with $2 \mathrm{mg} / \mathrm{m} l$ glycine in PBS for $10 \mathrm{~min}$, and then prehybridized in hybridization buffer $(0.1 \mathrm{M}$ Tris $\mathrm{HCl}$, pH 7.4, $1 \times$ Denhart's solution, $10 \%$ dextran sulfate, $50 \%$ deionized formamide containing $0.1 \mathrm{mg} / \mathrm{m} l$ salmon sperm DNA and $0.1 \mathrm{mg} / \mathrm{m} l$ yeast tRNA) for $1 \mathrm{hr}$ at RT. Digoxigenin (DIG)-labeled oligonucleotide probes for type I, III and IV collagen mRNAs [antisense probes for procollagen$\alpha_{1}(\mathrm{I}),-\alpha_{1}$ (III) and $-\alpha_{1}$ (IV) mRNAs, respectively] were mixed with hybridization buffer $(200 \mathrm{pM} / \mathrm{ml})$, and then applied on each section (50 $\mu \mathrm{l} / \mathrm{section})$. Sequences of oligoDNA probes for type I, III and IV collagens were TTTTA CCTTT GACCA ACTGA ACGTG ACCAA [5, 21], TATGA CATTG GGGGT CCTGA TCAAG AATTT [5, 21] and GTACC CCATC TGTGG ACCAT GGCTT 
CCTTG [22], respectively. The sections were incubated for $18 \mathrm{hr}$ at $37^{\circ} \mathrm{C}$ and washed as follows: 4 times $2 \times$ standard saline citrate (SSC) and $50 \%$ formamide for $60 \mathrm{~min}$ at $37^{\circ} \mathrm{C}$, 4 times $2 \times$ SSC containing $0.075 \%$ Brij-35 (Sigma) for 30 min at $37^{\circ} \mathrm{C}, 4$ times $0.5 \times \mathrm{SSC}$ containing $0.075 \%$ Brij-35 for $30 \mathrm{~min}$ at $37^{\circ} \mathrm{C}, 2$ times $0.2 \times \mathrm{SSC}$ containing $0.075 \%$ Brij- 35 for $30 \mathrm{~min}$ at $37^{\circ} \mathrm{C}$, and then 3 times $0.1 \mathrm{M}$ Tris- $\mathrm{HCl}$, $\mathrm{pH} 7.4$, containing $0.15 \mathrm{M} \mathrm{NaCl}$ for $5 \mathrm{~min}$ at RT. Immunohistochemical detection for each hybridized probe was performed using a Nucleic acid detection kit (Roche Diagnostics, Mannheim, Germany), according to the manufacturers' protocols. Briefly, the sections were rinsed with $1 \%$ blocking reagent diluted in $0.1 \mathrm{M}$ Tris- $\mathrm{HCl}, \mathrm{pH} 7.4,0.15$ $\mathrm{M} \mathrm{NaCl}$ (THS) for $1 \mathrm{hr}$ and incubated with alkaline phosphatase (AlP)-conjugated anti-DIG antibody (diluted 1/500 with THS) for $90 \mathrm{~min}$ at RT. After washing 3 times with THS for 5 min with $0.1 \mathrm{M}$ Tris-HCl, pH 9.5, 0.1 M NaCl and $0.05 \mathrm{M} \mathrm{MgCl}_{2}$ (alkaline buffer) for $5 \mathrm{~min}$, tissue sections were incubated with $0.4 \mathrm{mM}$ nitroblue tetrazolium (Sigma), 0.4 mM 5-bromo-4 chloro-3-indolylphosphate (Sigma) and $1 \mathrm{mM}$ levamisole (Sigma) in alkaline buffer for $2 \mathrm{hr}$ at $4^{\circ} \mathrm{C}$, and then rinsed with alkaline buffer. They were counter-stained with methyl green (Merck), mounted with Histofine (Nichirei, Tokyo, Japan) and examined with a microscope (BX51, Olympus, Tokyo, Japan). The specifity of the obtained in situ hybridization signal was verified by incubation with sense probe or without antisense probe as negative controls. As further negative controls, serial sections were processed by omission of the anti-DIG antibody. Any controls yielded completely negative results.

Statistical methods: ANOVA analysis with Fisher's least significant differences test comparison for biochemical data, and Wilcoxon's signed rank test for histopathological estimation were carried out with the StatView IV program using a Macintosh computer. Differences at a probability of $P<0.05$ were considered significant. All data are expressed as mean values $\pm \mathrm{SD}$ ( $\mathrm{n}=6$ mice in each group).

\section{RESULTS}

Clinical parameters: Aged ICGN mice (30-week-old) manifested clinical abnormalities such as exercise intolerance, pale ears and weight loss. Table 1 shows biochemical parameters that were measured to assess the renal function. ICGN mice showed severe hypoalbuminemia (1.49-fold decreases as compared with age-matched ICR mice; $P<0.001$ ) and albuminuria (no urinary albumin was detected in ICR mice). Marked increases were observed in $\mathrm{sCr}$ (3.00fold increases as compared with ICR mice; $P<0.001)$ and BUN (2.22-fold increase as compared with ICR mice; $P<0.001)$ in ICGN mice, indicating the loss of renal function in these animals. Increased sTC (1.70-fold increases as compared with ICR mice; $P<0.001)$ suggested severe hypercholesterolemia in ICGN mice. Thus, aged ICGN mice used in the present study were in the nephrotic state.

Kidney histopathology and collagen levels: As shown in Table 2, histopathological examination revealed that aged
Table 1. Serum and urine biochemical features in control ICR and ICGN mice

\begin{tabular}{lcc}
\hline & ICR mice & ICGN mice \\
\hline $\mathrm{sAlb}^{\mathrm{a})}(\mathrm{g} / \mathrm{d} l)$ & $3.18 \pm 0.13$ & $2.13 \pm 0.16^{* * *}$ \\
$\mathrm{uAlb}^{\mathrm{a})}(\mathrm{mg} / \mathrm{m} l)$ & not detected & $13.15 \pm 3.56$ \\
$\mathrm{sCr}^{\text {a) }}(\mathrm{mg} / \mathrm{d} l)$ & $0.30 \pm 0.03$ & $0.90 \pm 0.10^{* * *}$ \\
$\mathrm{BUN}^{\mathrm{a})}(\mathrm{mg} / \mathrm{d} l)$ & $31.8 \pm 1.9$ & $70.7 \pm 5.4^{* * *}$ \\
$\mathrm{sTC}^{\text {a) }}(\mathrm{mg} / \mathrm{d} l)$ & $120.2 \pm 5.1$ & $204.5 \pm 15.1 * * *$
\end{tabular}

a) For details, see Methods.

***: $P<0.001$ versus each control ICR mice.

Table 2. Histopathological changes of glomeruli, and total and type I collagen levels in the renal cortex of control ICR and ICGN mice

\begin{tabular}{lcl}
\hline & ICR mice & ICGN mice \\
\hline Normal $^{\text {a) }}(\%)$ & $97.8 \pm 1.2$ & $32.7 \pm 3.1^{* * * *}$ \\
Expansion of mesangial areas $^{\text {a) }}(\%)$ & $2.2 \pm 1.2$ & $54.8 \pm 3.8^{* * *}$ \\
Capillary aneurysma) $\left.^{\text {a }} \%\right)$ & not observed & $12.5 \pm 2.3$ \\
Total collagen $^{\text {b) }}(\mathrm{mg} / \mathrm{g}$ protein $)$ & $4.35 \pm 0.47$ & $7.52 \pm 0.43^{* * *}$ \\
Type I collagen $^{\mathrm{b})}(\mathrm{mg} / \mathrm{g}$ protein $)$ & $2.00 \pm 0.20$ & $3.50 \pm 0.20^{* * *}$
\end{tabular}

a) Histopathological changes are described in detail in Methods.

b) For details, see Methods.

$* * *: P<0.001$ versus each control ICR mice.

ICGN mice had abnormal kidneys $(54.8 \pm 3.8$ and $12.5 \pm$ $2.3 \%$ of kidney sections with expanded mesangial area and capillary aneurysm, respectively; $P<0.001$ ), but most agematched ICR mice $(97.8 \%)$ had normal kidneys. When compared with control ICR mice, enlargement of the mesangial region without cellular proliferation, tubulointerstial expansion, appearance of cysts, expansion of renal tubules, and infiltration of inflammatory cells were observed in the kidney sections of ICGN mice, and such histopathological abnormalities progressed in an age-dependent manner in ICGN mice. Moreover, as compared with ICR mice, progressed fibrotic change in the glomeruli and tubulointerstitum was observed in the kidney cortex area of ICGN mice, but no progressed fibrotic change was seen in the kidney medulla area. Thus, glomerulonephritic, and glomerular- and tubulointerstitial-fibrotic change became severe only in ICGN mice.

Total and type I collagen levels in the renal cortex sections of ICR and ICGN mice assessed by a microquantification method are shown in Table 2. ICGN mice showed 1.73-fold increases in total collagen levels $(P<0.001)$ and 1.75 -fold increases in type I collagen levels, as compared to controls $(P<0.001)$, indicating that fibrotic change in the renal cortex progressed in aged ICGN mice.

In situ hybridization: Moderate to strong expression of type I collagen mRNA was detected in glomeruli and proximal renal tubules with moderate and/or severe lesion in kidney sections of aged ICGN mice with manifested clinical abnormalities (Fig. 1B), but negative or trace expression of that was observed in those of ICR mice (Fig. 1A). In the kidneys of aged ICGN mice, type III collagen mRNA was detected in glomeruli and tubular epithelia (Fig. 1D). A part of interstitial myofibroblast-like cells were positive for type I and III collagen mRNAs (shown in inlets in Fig. 1B and 


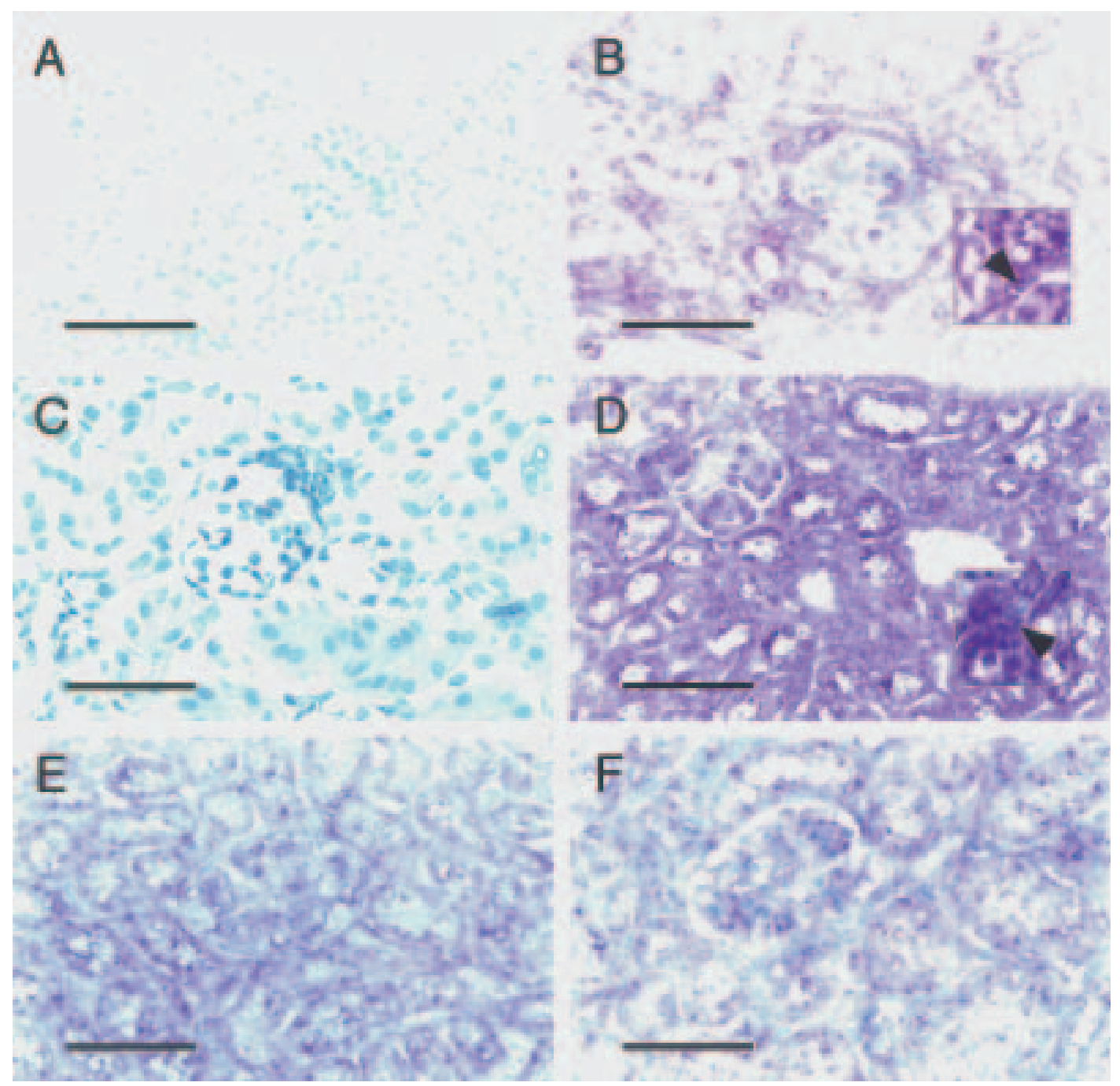

Fig. 1. Representative renal sections of ICR (A, C and E) and ICGN mice (B, D and F) were subjected to in situ hybridization with specific probes for procollagen $\alpha_{1}$ (I) (A and B), $\alpha_{1}$ (III) (C and D) and $\alpha_{1}$ (IV) (E and F) mRNAs. Inlets in $\mathrm{B}$ and $\mathrm{D}$ are interstitial regions, and arrowheads show positive interstitial cells. Scale bars indicate $50 \mu \mathrm{m}$.

D). Negative or trace reaction for Type III collagen mRNA was observed in the kidneys of ICR mice (Fig. 1C). No remarkable differences were seen in the localization of type I and III collagen mRNAs in the kidneys of aged ICGN mice. Slight expression of type IV collagen mRNA was demonstrated in every renal tubules in kidneys of both ICGN and ICR mice, and no remarkable difference in the expression of that was noted between these mice.

\section{DISCUSSION}

Chronic renal disease is characterized by clinical and morphological features caused by a progressive and irreversible loss of renal function. ICGN mice, a spontaneous nephrotic model, are considered a useful model for pathogenic analyses of progressive and chronic nephrotic syn- drome and for investigating not only nephrotic conditions but also the cellular and molecular pathogenesis of diffuse mesangial sclerosis in steroid-resistant infantile nephrotic syndrome $[9,10]$. Moreover, recent studies using the ICGN mice showed that an angiotensin converting enzyme inhibitor can attenuate the progress of renal dysfunction and fibrosis [8], and that recombinant hepatocyte growth factor (HGF) inhibits the onset of tubulointerstitial fibrosis and attenuates the progression of glomerulosclerosis $[9,10]$. ICGN mice are believed to be a useful hereditary animal model for evaluation of therapeutic agents for nephrotic syndrome.

We demonstrated that both interstitial and membranous ECM components were abnormally accumulated in renal glomeruli and tubulointerstitium of ICGN mice, and such ECM accumulation developed in an age-dependent manner 
[26]. As the mechanisms responsible for the excessive accumulation of ECM components in the kidneys of ICGN mice have not yet been revealed, we compared the activities of MMPs in the kidneys of aged ICGN mice and agematched ICR mice, and revealed that lower activities of collagenase (MMP-1) and gelatinase (MMP-2 and -9) were demonstrated in the kidneys of ICGN mice as compared with those of ICR mice, but there were no significant differences in the stromelysin (MMP-3) activities between these mice [27]. These results indicate that decrease of MMP activity is one of the causes for abnormal accumulation of ECMs in ICGN mouse kidneys. Extremely low levels of ECM degradation together with reduced ECM production cause abnormal ECM accumulation, and extremely high levels of ECM production together with increased ECM degradation also cause abnormal ECM accumulation [1, 3, $4,23,24]$. Clarification of the balance between the rates of ECM production and degradation is necessary to explain the abnormal ECM augmentation in the tissues with pathological conditions, but this balance has not been fully determined in the kidneys of ICGN mice. In the present study, to reveal the mechanisms of abnormal ECM accumulation in the kidneys of ICGN mice, we investigated the localization of mRNAs of interstitial type I and III collagens and membranous type IV collagen, because these collagens were excessively accumulated in the kidneys of aged ICGN mice [26]. In situ hybridization for these mRNAs showed that increased expression of mRNAs of type I and III collagens were detected in glomeruli and expanded proximal tubules of aged ICGN mice, but no notable difference in the localization of type IV collagen mRNA, which was demonstrated in all glomeruli and tubule regions, was seen between the kidneys of ICR and ICGN mice. Our findings of the localization of type I and III collagen proteins assessed by immunohistochemical stainings [26] were correspond with the present data of the localization of their mRNAs. Excessive accumulation of type IV collagen protein was immunohistochemically demonstrated in glomeruli and tubulointerstitum of ICGN mice [26], but no distinct changes in the localization of type IV collagen mRNA. We biochemically showed that lower activities of MMP-1 and MMP-2 and -9 were demonstrated in the kidneys of ICGN mice as compared with those of ICR mice [28], indicating that lower levels of MMPs may cause excessive accumulation type IV collagen. The present in situ hybridization studies demonstrated that increased production levels of interstitial collagens but not of membranous ones were concluded in the kidneys of aged ICGN mice. We immunohistochemically demonstrated the increased level of the active form of TGF$\beta_{1}$, which promotes ECM synthesis and suppresses its breakdown [1, 4], in the kidney sections of ICGN mice with progressed renal failure [26]. In the kidneys, the balance of TGF- $\beta_{1}$, which acts as an accelerator, and HGF, which acts as an inhibitor, is considered crucial in the progression of renal fibrotic change $[9,10]$. Not only an increase in TGF$\beta_{1}$ levels but also a decrease in local HGF levels may be responsible for the manifestation of renal fibrosis, particu- larly tubular destruction. High level of TGF- $\beta_{1}$ and low level of HGF cause renal fibrosis [26, 27], and recombinant human HGF treatment prevents the progression of renal fibrotic change in ICGN mice [10-12]. Moreover, we immunohistochemically demonstrated the abnormal localization of integrins, specific ECM receptors, corresponding for the fibrotic change in the kidneys of ICGN mice [28]. We immunohistochemically compared the cell kinetics (localization of proliferating cells and apoptotic cells) in the kidneys of ICGN mice with ICR mice [31]. Proliferating glomerular mesangial cells, epithelial cells of renal tubules and tublointerstitial myofibroblast-like cells were observed in the kidneys of ICGN mice, but no proliferating cells were seen in those of ICR mice. Apoptotic cells were observed only in the tubulointerstitium in the kidneys of ICGN mice but not in those of controls. These proliferating mesangial cells and epithelial cells produce type I and III collagens, and a part of tublointerstitial cells produce interstitial collagens. Because a part of tublointerstitial cells may be a process of apoptotic cell death and a part of them may not be mature, such tublointerstitial cells can not produce interstitial collagens. Increased population of these fibrogenic cells and activated metabolisms of ECM production may cause severe fibrotic change in the kidneys of ICGN mice. The proliferation of renal tubular epithelial cells may represent a compensatory response, and that of mesangial and myofibroblast-like cells may play a pathogenic role in nephrotic syndrome.

We concluded that excessive accumulation of interstitial type I and III collagens in kidneys of ICGN mice is caused by increased production of these collagens and decreased degradation of them, and that moderate accumulation of membranous type IV collagen is caused by decreased degradation but not increased production. Interstitial collagen accumulation may be caused by activation of TGF- $\beta_{1}$. Interestingly, the mechanisms of ECM accumulation of interstitial collagens are different from those of membranous collagen. Our findings should contribute to elucidation of the mechanism of excessive accumulation of ECMs in patients with hereditary nephrotic syndrome. Further detailed studies to reveal the pathogenic causes of the renal failure in ICGN mice, especially how to upregulate the collagen mRNAs and to activate the TGF- $\beta_{1}$, are in progress in our laboratory.

ACKNOWLEDGEMENTS. We are grateful to Drs. M. Nakayama and N. Akashi for excellent assistances. A part of this work was supported by a Grant-in-Aid for Creative Scientific Research (13GS0008), to N. M. from the Ministry of Education, Culture, Sports, Science and Technology of Japan. K. U. and M. Y-Y. were received Research Fellowship for Young Scientist of the Japan Society for the Promotion of Science.

\section{REFERENCES}

1. Border, W. A. and Ruoslahti, E. 1992. Transforming growth 
factor- $\beta_{1}$ in disease: the dark side of tissue repair. J. Clin. Invest. 90: $1-7$.

2. Davis, M., Martin, J., Thomas, G. J. and Lovett, D. H. 1992. Proteinases and glomerular matrix turnover. Kidney Int. 41: 671-678.

3. Harendza, S., Schneider, A., Helmchen, U. and Stahl, R. A. K. 1999. Extracellular matrix deposition and cell proliferation in a model of chronic glomerulonephritis in the rat. Nephrol. Dial. Transplant. 14: 2873-2879.

4. Kim, T. S., Kim, J. Y., Hong, H. K. and Lee H. S. 1999. mRNA expression of glomerular basement membrane proteins and TGF- $\beta_{1}$ in human nephropathy. J. Pathol. 189: 425-430.

5. Lukinmaa, P. L., Vaahtokari, A., Vainio, S., Sandberg, M., Waltimo, J. and, Thesleff, I. 1993. Transient expression of type III collagen by odontoblasts: developmental changes in the distribution of pro- $\alpha_{1}$ (III) and pro- $\alpha_{1}$ (I) collagen mRNAs in dental tissues. Matrix 13: 503-515.

6. Manabe, N., Furuya, Y., Nagano, N., Yagi, M., Kutamitsu, K. and Miyamoto, H. 1995. Immunohistochemical quantitation for extracellular matrix proteins in rats with glomerulonephritis. Nephron 71: 79-86.

7. McMillan, J. I., Rioedan, J. W., Couser, W. G., Pollock A. S. and Lovett, D. H. 1996. Characterization of a glomerular epithelial cell metalloproteinases as matrix metalloproteinase-9 with enhanced expression in a model of membranous nephropathy. J. Clin. Invest. 97: 1094-1101.

8. Mizuno, S., Horikawa, Y., Okamoto, M. and Kurosawa, T. 1998. Preventive effect of ACE inhibitor on interstitial myofibroblast formation and matrix deposition in a nephrotic model. Renal Failure 20: 481-491.

9. Mizuno, S., Kurosawa, T., Matsumoto, K., Mizuno-Horikawa, Y., Okamoto, M. and Nakamura, T. 1998. Hepatocyte growth factor prevents renal fibrosis and dysfunction in a mouse model of chronic renal disease. J. Clin. Invest. 101: 1827-1834.

10. Mizuno, S., Matsumoto, K., Kurosawa, T., Mizuno-Horikawa, Y. and Nakamura, T. 2000. Reciprocal balance of hepatocyte growth factor and transforming growth factor- $\beta_{1}$ in renal fibrosis in mice. Kidney Int. 57: 937-948.

11. Mizuno, S., Mizuno-Horikawa, Y., Yue-Bing, F., Okamoto, M. and Kurosawa, T. 1999. Nephrotic mice (ICGN strain): a model of diffuse mesangial sclerosis in infantile nephrotic syndrome. Am. J. Nephrol. 19: 73-82.

12. Mizuno, S., Yue-Bing F., Okamoto, M., Horikawa, Y. and Kurosawa, T. 1997. Diffuse glomerulosclerosis without tubular injury does not directly manifest renal dysfunction in nephrotic mice (ICGN strain). Exp. Nephrol. 5: 498-507.

13. Nakayama, N., Manabe, N., Yamada-Uchio, K. and Miyamoto, H. 2001. Changes in localization of type I, III and IV collagens and their mRNA expression during follicular atresia in bovine and porcine ovaries. J. Reprod. Dev. 47: 27-36.

14. Ogura, A., Asano, T., Matsuda, J. and Fujimura, H. 1991. Evolution of glomerular lesions in nephrotic ICGN mice: serial biopsy study with electron microscopy. J. Vet. Med. Sci. 53: 513-515.

15. Ogura, A., Asano, T., Matsuda, J., Koura, M., Nakagawa, M., Kawaguchi, H. and Yamaguchi, Y. 1990. An electron microscopic study of glomerular lesion in hereditary nephrotic mice (ICGN strain). Virch. Arch. Pathol. Anat. 417: 223-228.

16. Ogura, A., Asano, T., Matsuda, J., Noguchi, Y., Yamamoto, Y., Takano, K. and Nakagawa, M. 1989. Development of nephrotic ICGN mice: the origin, reproductive ability, and incidence of glomerulonephritis. Exp. Anim. (Tokyo) 38: 349-352.
17. Ogura, A., Asano, T., Matsuda, J., Takano, K., Nakagawa, M. and Fukui M. 1989. Characteristics of mutant mice (ICGN) with spontaneous renal lesion: a new model for human nephrotic syndrome. Lab. Anim. 23: 169-174.

18. Ogura, A., Asano, T. and Fujimura, H. 1994. Animal model of human disease: inherited nephrotic syndrome. Comp. Pathol. Bull. 26: 3-6.

19. Ogura, A., Asano, T., Suzuki, O., Yamamoto, Y., Noguchi, Y., Kawaguchi, H. and Yamaguchi, Y. 1994. Hereditary nephrotic syndrome with progression to renal failure in a mouse model (ICGN strain): clinical study. Nephron 68: 239-244.

20. Ogura, A., Fujimura, H., Asano, T., Koura, M., Naito, I. and Kobayashi, Y. 1995. Early ultrastructural glomerular alteration in neonatal nephrotic mice (ICGN strain). Vet. Pathol. 32: 321-323.

21. Prockop, D. J. and Kivirikko, K. I. 1995. Collagens: molecular biology, diseases and potentials for therapy. Annu. Rev. Biochem. 64: 403-434.

22. Sarthy, V. 1993. Collagen IV mRNA expression during development of the mouse retina: an in situ hybridization study. Invest. Ophthalmol. Vis. Sci. 34: 145-152.

23. Schnaper, H. W., Kopp, J. B., Poncelet, A. C., Hubchack S. C., Stetler-Stevenson W. G., Klotman, P. E. and Kleinmen H. K. 1996. Increased expression of extracellular matrix proteins and decreased expression of matrix protease after serial passage of glomerular mesangial cells. J. Cell Sci. 109: 2521-2528.

24. Suzuki, D., Miyazaki, M., Jinde, K., Koji, T., Yagame, M., Endoh, M., Nomoto, Y. and Sakai, H. 1997. In situ hybridization studies of matrix metalloproteinase-3, tissue inhibitor of metalloproteinse-1 and type IV collagen in diabetic nephropathy. Kidney Int. 52: 111-119.

25. Tamura, K., Manabe, N., Uchio, K., Miyamoto, M., Ogura, A., Yamamoto, Y., Nagano, N., Furuya, Y. and Miyamoto, H. 2000. Characteristic changes in carbohydrate profile in the kidneys of hereditary nephrotic mice (ICGN strain). J. Vet. Med. Sci. 62: 379-390.

26. Uchio, K., Manabe, N., Kinoshita, A., Tamura, K., Miyamoto, M., Ogura, A., Yamamoto, Y. and Miyamoto, H. 1999. Abnormalities of extracellular matrices and transforming growth factor $\beta_{1}$ localization in the kidney of the hereditary nephrotic mice (ICGN strain). J. Vet. Med. Sci. 61: 769-776.

27. Uchio, K., Manabe, N., Tamura, K., Miyamoto, M., Ogura, A., Yamamoto, Y. and Miyamoto, H. 2000. Decreased matrix metalloproteinase activity in the kidneys of hereditary nephrotic mice (ICGN mice). Nephron 86: 145-151.

28. Uchio-Yamada, K., Manabe, N., Yamaguchi, M., Akashi, N., Yamamoto, Y., Ogura, A. and Miyamoto, H. 2001. Localization of extracellular matrix receptors in ICGN mice, a strain of mice with hereditary nephrotic syndrome. J. Vet. Med. Sci. 62: 1171-1178.

29. Uchio-Yamada, K., Tuchweber, B., Manabe, N., Gabbiani, G., Rosenbaum, J. and Desmouliere, A. 2002. Cellular retinolbinding protein-1 expression and modulation during in vivo and in vitro myofibroblastic differentiation of rat hepatic stellate cells and portal fibroblasts. Lab. Invest. 82: 619-628.

30. Werb, Z. 1997. ECM and cell surface proteolysis: regulating cellular ecology. Cell 91: 439-442.

31. Yamaguchi, M., Manabe, N., Uchio-Yamada, K., Akashi, N., Yamamoto, Y., Ogura, A. and Miyamoto, H. 2001. Localization of proliferative and apoptotic cells in the kidneys of ICRderived glomerulonephritis (ICGN) mice. J. Vet. Med. Sci. 62: 781-787. 